\title{
A review of psychosocial factors and stroke : A new public health problem
}

\author{
M. Graber ${ }^{a}$, L. Baptiste ${ }^{a}$, S. Mohr ${ }^{a}$, C. Blanc-Labarre ${ }^{a}$, \\ G. Dupont ${ }^{\mathrm{a}}$, M. Giroud ${ }^{\mathrm{a}}$, Y. Béjot ${ }^{\mathrm{a}}$
}

a. Service de Neurologie générale, vasculaire et dégénérative CHU Dijon Bourgogne et Registre Dijonnais des AVC (Inserm, Santé Publique France, EA7460) - University of Burgundy and Franche Comté

\section{Epreuves et Tirés à part :}

Pr Maurice Giroud

Service de Neurologie générale, vasculaire et dégénérative

CHU Dijon Bourgogne

14 Rue Paul Gaffarel

21079 Dijon Cedex

Tél. : 03.80.29.32.45 - Fax : 03.80.29.32.76

maurice.giroud@chu-dijon.fr 


\section{Abstract}

The role of psychosocial factors (PSF) in increased risk of stroke is a novel public health challenge, but unclear definitions for PSF and the multiple stroke subtypes have led to inconsistent reports. A review of this issue is therefore warranted.

\section{Methods}

Several databases were used for this narrative systematic review (Medline, Embase and Cochrane Library). Two independent reviewers evaluated articles from between 2001 and 2018 on the themes of PSF and stroke / transient ischemic attack (TIA). PSF criteria were job strain, psychological interpersonal and behavioral stress, and social deprivation. Ischemic and hemorrhagic stroke and TIA subtypes were also identified.

\section{Results}

Forty-seven cohorts, seven case-control studies and two meta-analyses were included. Despite mixed results, PSF were associated with an increased risk of ischemic and hemorrhagic stroke in populations of all ages, and more predominantly in women.

\section{Conclusion}

This broad review shows that the presence of PSF is associated with an increased risk stroke and TIA. As such, PSF must figure in both public health policy and stroke prevention programs, similar to other established metabolic and environmental factors.

\section{Key-words}

Stroke, TIA, Psychosocial factors, stress, risk factors, environmental factors 


\section{Introduction}

Stroke is the primary cause of motor handicap in adulthood, the second cause of cognitive decline after Alzheimer disease and the second cause of death in both women and men, making it a major public health problem [1-4].

Along with ischemic heart disease, stroke is a disease for which the risk factors have been clearly identified: 10 risk factors are responsible for $90 \%$ of strokes [1,5]. Psychosocial factors (PSF), whose influence on myocardial infarction is well known [6], have an unclear role in stroke risk [7] for several reasons. Stroke is an umbrella term for five diseases : large-artery atherosclerosis, cardioembolism, small-artery occlusion (lacune), stroke of other determined causes, and stroke of undetermined causes [8]. Classical psychosocial stressors are perceived factors such as job strain, psychosocial stress, behavioral characteristics, interpersonal problems and social deprivation.

Job strain or work-place stress are increasingly recognized as societal issues [9-13] with two parameters measuring the well-being of employees: their self-satisfaction status and their adaptation to the work. To the other side, it has been demonstrated that the incidence rates for stroke is increasing in active professionals aged less than 55 years $[2,14,15]$.

The objective of the present study was to conduct a narrative systematic review to establish whether PSF increases the risk of stroke and transient ischemic attacks (TIA).

\section{Methods}

We explored articles from between 2001 and June 2018 indexed in Medline, Embase, and Cochrane Library. We limited our search to articles with the following keywords in the title: psychological factors (depression, mood, anger, anxiety, distress, stress, self-esteem, life satisfaction); behavioral factors (ambition, coping); interpersonal relationships (emotion, social activity, isolation, happy and sad life events, quality of family life, quality of leisure); occupational factors (type of work, job satisfaction, working duration, shift work, education level); and social deprivation.

We retained studies that used a standard definition of stroke and TIA $[1,2,8,9,16]$ for ischemic and hemorrhagic stroke, subarachnoid hemorrhage, and which reported on recognized vascular risk factors (high blood pressure, diabetes, hypercholesterolemia, smoking, atrial fibrillation, obesity) $[1,5,17]$.

Studies were included if they adhered to the abovementioned criteria. Articles were excluded if they did not use the usual criteria for stroke and PSF or were in the form of conference abstracts.

Two investigators ( $\mathrm{MGr}, \mathrm{MGi}$ ) independently evaluated all retrieved studies for eligibility and performed data extraction. Any discordance between investigators was resolved through discussion.

\section{Results}

Overall, 56 studies were retained: 47 cohort studies, 7 case-control studies and 2 meta-analyses.

Twenty-four cohort studies investigated psychological risk factors [18-41], 13 of them occupational risk factors $[11,13,35,40,42-50]$ (Table 1 ), 8 of them interpersonal risks $[24,40,42,48,51-54]$, and 2 of them behavioral risks $[55,56]$ (Table 2 ).

The case-control study by 0'Donnell et al. [5] was the first to demonstrate a strong, statistically significant positive relationship between overall PSF and stroke (OR 2.20, 99\% $\mathrm{Cl} 1.78-2.72$ ), among the classical risk factors for stroke.

Among the case-control studies, 2 focused on psychological risks [57,58], 2 interpersonal risks $[59,60]$, 2 social deprivation $[61,62]$ and 1 looked at overall psychological risks [5] (Table 3) .

The 2 meta-analyses $[9,10]$ provided data on global psychosocial risk factors for stroke (Table 4). Most of the studies demonstrated a significant positive association between PSF and stroke risks, and 22 of the 56 studies found a positive but not significant association (Tables 1-4). 
Some discrepancies were observed related to a problem of small number of patients. One study [27] observed a non-significant positive association in patients older than 65 years. Five studies $[13,33,45,46,59]$ observed a non-significant positive association in women, while $2[37,47]$ observed a non-significant association in men.

To the opposite, 2 studies reported a significant association between PSF and stroke for women $[37,43]$ and 5 for men $[32,43,45,46,59]$. One study [11] observed a significant positive association for ischemic stroke, but not for hemorrhagic stroke. Three studies observed a paradoxical protective effect for psychological risk [33], occupational risk in women [46] or behavioral risk [55].

Finally, the 2 available meta-analyses $[9,10]$ and the cohort-study by O'Donnell et al. [5] found a significant positive association between overall psychosocial risks and stroke.

The meta-analysis by Booth et al. [10] pooled the data from 14 studies. They found that the adjusted effect estimate for overall risk of stroke in patients exposed to work stress or to stressful life events was 1.33 (95\% confidence interval $[\mathrm{Cl}] 1.17-1.50, \mathrm{P}<0.00001)$. Psychosocial stress was associated with an increased risk of fatal stroke (hazard ration [HR] 1.45, $95 \% \mathrm{Cl} 1.19-1.78, \mathrm{P}=0.002$ ) and ischemic stroke ( $\mathrm{HR} 1.40,95 \% \mathrm{Cl} 1.00-1.97, \mathrm{P}>0.0001)$. They observed a higher risk of stroke in women (HR $1.90,95 \% \mathrm{Cl} 1.40-2.56, \mathrm{P}<0.0001)$ than in men (HR 1.24, 95\% Cl 1.12-1.36, $\mathrm{P}<0.0001)$.

In 2017, Lightbody et al. [9] evaluated 41 cohort studies and 5 case-controls studies. Overall pooled adjusted estimates showed that psychosocial risk factors were an independent risk factor for stroke: they reported that psychological stress increased the risk of stroke by $39 \%$ (HR 1.39, 95\% Cl 1.27-1.51), occupational stress by $35 \%$ (HR 1.35, 95\% Cl 1.20-1.51), and interpersonal stress by $16 \%$ (HR 1.16, $95 \% \mathrm{Cl} 1.03-1.31$ ), whereas the effects of behavioral factors were not significant (HR 0.94, $95 \% \mathrm{Cl} 0.20$ 4.31).

Unusual factors, mainly social deprivation, were analyzed in a number of other studies $[42,43,50,61$ 63]. Stroke incidence was found to increase with social deprivation (OR 1.34; $P=0.003$ ) [61]. After discharge, age- and gender-adjusted mortality gradually increased with social deprivation, as measured by the Towsend Deprivation Score (HR $2.08 ; 95 \% \mathrm{Cl}$ 1.07-4.02) [63]. The most deprived patients presented a significantly higher risk of both mild and moderate/severe stroke (OR 1.44, $95 \%$ Cl 1.09-1.92) [62].

\section{Discussion}

Studies that have focused on modifiable risk factors for acute stroke without factoring in PSF [1] may underestimate the influence of personal, psychological, behavioral, social deprivation and occupational burden on stroke risk [5].

Our review of 56 studies, which includes 47 cohort-studies, 7 case-control studies and 2 meta-analyses, brings together the data from more than 10.000 strokes. The studies seen here demonstrate a statistically positive association between PSF and both ischemic and hemorrhagic stroke, in men and women. This positive association was seen in cohort studies, case-control studies and meta-analyses. The robust latest results of Lightbody et al. [9] demonstrated that psychological factors increased the risk of stroke by $39 \%$, occupational risks by $35 \%$, interpersonal risk by $16 \%$. In addition, our team has previously demonstrated that social deprivation are associated with increased risk of stroke [61], stroke severity [62] and mortality [63].

Despite a marked heterogeneity $\left(I^{2} \geq 60 \%\right)$, the sensitivity analyses conducted by Lightbody et al. [9] which were adjusted for the heterogeneous study types and various PSF, demonstrated that the risk estimates were significant. Some limitations may explain this heterogeneity. 
The first bias is related to the confounders. While Lightbody et al. [9] included studies that have adjusted to potential cofounders, some studies adjusted for only 4 cofounders [43], and others adjusted for $16[48,54,56]$.

Another limitation is the definition of PSF, psychological, occupational and interpersonal factors, whose scopes are more or less broad according to the studies. In this review, we added social deprivation to psychological, occupational, interpersonal and behavioral factors because it is another robust risk factor for stroke.

Other PSF such as long working hours [64-66], short sleep cycles [67], and social deprivation [50,6163 ] were sometimes added. All of these factors, which may further influence occupational stress, life satisfaction and quality of life, were found to increase the risk of stroke.

The use of a single question, subjective responses, the length of exposure to PSF, the type of PSF, the burden of job strain [11-13] or negative life events, depression [68-70] and atrial fibrillation [65,66], may worsen the heterogeneity of the results.

Age is another significant bias. The age groups in the studies ranged from 18 [78] to 100 years [27], meaning that there were variations in stroke incidence. Duration of exposition to PSF varied between 5 to 30 years [10]. Eight cohort studies included only men or women [19,25,36,38,42,49,50,55].

Medical history was inconsistent, and key data regarding blood pressure, atrial fibrillation, diabetes, smoking, sleep habits and working hours was often lacking.

Psychological factors are a cluster of symptoms from panic attacks to schizophrenia to depression [35,68-70]. These factors may induce a bias even if localized in the right category and, additionally, measures of psychosocial exposure are not homogeneous: less than $50 \%$ of the studies evaluate exposure with a validated tool [9].

We can also observe that repeated measures were not performed, thus limiting the reliability of the results.

However, O'Donnell et al.'s case-control study [5] and the 2 meta-analyses $[9,10]$ were able to reduce the number of biases, confirming the importance and the depth of the interaction between PSF and stroke.

The strength of this review is based on the number of validated studies summarized in the systematic review and meta-analyse of Lightbody et al. [9], and the multiple sources of the homogeneous studies. The reality of this association is demonstrated by the prospective work of Becher et al [71] which demonstrated the efficacy of a psychosocial safety climate compared to an usual psychosocial policy.

\section{Biological mechanisms of the PSF-stroke association}

These results indicate a need to improve the understanding of the underlying mechanisms of PSF. For instance, it is already known that PSF may trigger autonomic nervous system reactions $[9,10,72]$.

Possible processes, though not fully validated, are vascular inflammation, oxidative stress [10], activation of hypothalamic axis, catecholamine and cortisol release, stress-induced auricular fibrillation [12,73], hypertension, hippocampal stimulation [72], C-reactive protein and interleukin release [9]. Behavioral risk (alcohol, cannabis and tobacco abuse) may also be influenced by underlying mechanisms [73]. It has also been postulated that each PSF may have a specific independent impact on stroke risk $[12,56]$. A further understanding of such mechanisms may provide important advances for the prevention of stroke.

\section{Identification of at-risk populations}

This review highlights a population at risk of stroke. Both the research and prevention should turn their attention to those who experience occupational stress and shift work, stress at home, depression, anxiety, long working hours and short sleep cycles, social deprivation, with particular attention paid to 
the presence of proven stroke factors like high blood pressure, smoking, alcohol, diabetes, and atrial fibrillation $[1,12,74-76]$.

\section{Recommendations for future research}

Further prospective epidemiological studies are required to determine associations between PSF and stroke subtypes, both for the risk of first-ever and recurrent stroke. Future studies should identify the effects of the accumulation of various PSF subtypes and the role of each, the mechanisms of the causeeffect associations, possible synergistic effects of PSF and classical risk factors for stroke, and the respective place of acute and chronic exposure to PSF.

\section{Recommendations for practice}

As it is not possible to identify a threshold between safe and dangerous levels of PSF, health policy must work towards raising awareness in the workplace about the role of PSF as a risk factor for stroke.

\section{Conclusion}

Though the true amplitude of the issue is not yet known, this review brings attention to a novel public health problem by demonstrating that PSF are independent risk factors for stroke. Further studies are needed to understand the direct mechanisms underlying this association and to confirm the causal links necessary to promote primary and secondary prevention.

This problem is particularly important in developed countries where the incidence rates of stroke are increasing in relatively young populations who are still fully engaged in occupational and personal pursuits.

The results of this review could have a public health impact if the reported association is seen as a serious but modifiable vascular risk factor.

Indeed, awareness of this association should be included in public health policy and in primary and secondary stroke prevention programs $[9,10,74,77,78]$ and psychological health must be promoted in the workplace more specifically [71].

We can conclude that there is an existing link between PSF and the risk of stroke $[5,9,10]$, but it will not be possible to establish the level of risk until more data becomes available.

Disclosure of interest : no disclosure of interest

Acknowledgments : we would like to thank Suzanne Rankin for reviewing the English used in this manuscript 
[1] Feigin VL, Roth GA, Naghavi M, Parmar P, Krishnamurthi R, Chugh S et al. Global Burden of stroke and risk factors in 188 countries, during 1990-2013 : a systematic analysis for the Global Burden of Diseases Study 2013. Lancet Neurol 2016.doi.org/10.1016/S1474-4422(16) 30073-4.

[2] Lecoffre C., de Peretti C., Gabet A., Grimaud O., Woimant F., Giroud M., et al. (2017).

L'accident vasculaire cérébral en France : patients hospitalisés pour AVC en 2014 et évolutions 2008-2014. BEH 2017;7;(5):84-94.

[3] Guéniat J, Brenière C, Graber M, Garnier L, Mohr S, Giroud M et al. Increasing burden of stroke. The Dijon Stroke Registry (1987-2012). Neuroepidemiology 2018;50:47-56.

[4] World Health Organization. The top 10 causes of death worldwide. 2017.http://www.who.int/mediacenter/factsheets/fs310/en/? Accessed March, 2017.

[5] O'Donnell MJ, Chin SL, Rangarajan S, Xavier D, Liu L, Zhang $\mathrm{H}$ et al. Global and regional effects of potentially modifiable risk factors associated with acute stroke in 32 countries (INTERSTROKE) : a case-control study. The Lancet 2016;388:761-75.

[6] Rosengren A, Hawken S, OunpuS, Sliwa K, Zubaid M, Almahmed W et al. Association of psychosocial risk factors with risk of acute myocardial infarction in 11119 cases and 13648 controls from 52 countries (the INTERHEART study): case-control study. Lancet 2004;364:953-62.

[7] Muller-Nordhorn J, Nolte $\mathrm{CH}$, Rossnagel K, Jungehulsing G, Reich A, Roll S et al. Knowledge about risk factors for stroke. A population-based survey with 28090 participants. Stroke 2006;37:946-50.

[8] Adams HP, Bendixen BH, Kappelle L, Biller J, Love BB, Gordon LL et al. Classification of subtype of acute ischemic stroke. Definition for use in a multicenter clinical trial. TOAST. Trial of Org 10172 in Acute Stroke Treatment. Stroke 1993;24(1):35-41.

[9] Lightbody CE, Clegg A, Patel K, Lucas JM. Systematic review and meta-analysis of psychosocial risk factors for stroke. Semin Neurol 2017;37(03):294-306.

[10] Booth J, Connelly L, Laurence M, Chalmers C, Joice S, Becker C, et al. Evidence of perceived psychosocial stress as a risk factor for stroke in adults : a meta-analysis. BMC Neurology 2015;15:233-45.

[11] Fransson El, Nyberg ST, Heikkilä K, Alfredsson L, Bjorner JB, Borritz $\mathrm{M}$ et al. Job strain and the risk of stroke : an individual participant data meta-analysis. Stroke 2015;46(2):557-9.

[12] Fransson El, Nordin M, Hanson M, Westerlund H. Job strain and atrial fibrillation : results from the swedish longitudinal occupational survey of health and meta-analysis of three studies. Europ J of Preventive Cardiology 2018.doi.org/10.1177/2047487318777387.

[13] Huang $Y, X u ~ S$, Hua J, Zhu D, Lice C, Hu Y et al. Association between job strain and risk of incident stroke : a meta-analysis. Neurology $2015 ; 85(19): 1648-54$. 
[14] Béjot Y, Daubail B, Jaquin A, Durier J, Osseby GV, Rouaud O et al. Trends in the incidence of ischemic stroke in young adults between 1985 and 2011 : the Dijon Stroke Registry. J Neurol Neurosurg Psychiatry 2014;85:985-90.

[15] Krishnamurthi RV, Moraon AE, Feigin VL, Barker-Collo S, Norving B, Mensah GA et al. Stroke prevalence, mortality and disability-adjusted life years in adults aged 26-64 years in 19902013 : data from the Global Burden of Disease 2013 study. Neuroepidemiology 2015;45:190202.

[16] Béjot $Y$, Brenière $C$, Graber $M$, Garnier L, Durier J, Blanc $C$ et al. Contemporany epidemiology of transient ischemic attack in Dijon, France (2013-2015). Neuroepidemiology 2017;49:13541.

[17] Khoumri C, Bailly H, Delpont B, Daubail B, Blanc C, Chazalon C et al. Temporal trends in the premorbid use of preventive treatments in patients with acute ischemic cerebrovascular events and a history of vascular disease : the Dijon Stroke Registry (1985-2010). La Presse Médicale 2017.doi.org/10.1016/j.lpn.2017.01.025.

[18] Ohira T, Iso H, Satoh S, Sankai T, Tanigawa T, Ogawa Y et al. Prospective Study of Depressive Symptoms and Risk of Stroke Among Japanese. Stroke 2001;32:903-8.

[19] May M, McCarron P, Stansfeld S, Ben-Shlomo Y, Gallacher J, Yarnell J et al. Does Psychological Distress Predict the Risk of Ischemic Stroke and Transient Ischemic Attack ? The Caerphilly Study. Stroke 2002;33:7-12.

[20] Truelsen T, Nielsen N, Boysen G, Gronbaek M. Copenhagen City Heart Study. Self-reported stress and risk of stroke : the Copenhagen City Heart Study. Stroke 2003;34:856-62.

[21] Ohlin B, Nilsson PM, Nilsson JA, Berglund G. Chronic psychosocial stress predicts long-term cardiovascular morbidity and mortality in middle-aged men. European Heart Journal 2004;25:867-73

[22] Nilsson FM, Kessing LV. Increased risk of developing stroke for patients with major affective disorder : a registry study. Eur Arch Psychiatry Clin Neurosci 2004;254:387-91.

[23] Curkendall SM, Mo J, Glasser DB, Stang MR, Jones JK. Cardiovascular disease in patients with schizophrenia in Saskatchewan, Canada. J Clin Psychiatry 2004;65:715-20.

[24] Araki A, Murotami Y, Kamimiya F, Itoh $\mathrm{H}$. Low well-bellijg is an independent predictor of stroke in elderly patients with diabetes mellitus. J Am Geriatr Soc 2004;52:205-10.

[25] Smoller JW, Pollack MH, Wassertheil-Smoller S, Jackson RD, Oberman A, Wong ND et al. Panic Attacks and Risk of Incident Cardiovascular Events Among Postmenopausal Women in the Women's Health Initiative Observational Study. Arch Gen Psychiatry 2007;64(10):1153-60. 
[26] Lin H-C, Tsai S-Y, Lee H-C. Increased risk of developing stroke among patients with bipolar disorder after an acute mood episode : a six-year follow-up study. Journal of affective disorders 2007;100:49-54.

[27] Salaycik KJ, Kelly-Hayes M, Beiser A, Nguyen AH, Brady SM, Kase CS et al. Depressive symptoms and risk of stroke : the Framingham study. Stroke 2007;38:16-21.

[28] Arbelaez JJ, Ariyo AA, Crum RM, Fried LP, Ford DE. Depressive symptoms, inflammation and ischemic stroke in older adults : a prospective analysis in the cardiovascular health study. J Am Geriatr Soc 2007;55:1825-30.

[29] Surtees PG, Wainwright NWJ, Luben RL, Wareham NJ, Bingham SA, Khaw K-T. Psychological distress, major depressive disorder, and risk of stroke. Neurology 2008;70:788-94.

[30] Lee H-C, Lin H-C, Tsai S-Y. Severely depressed young patients have over five times increased risk for stroke : a 5-year follow-up study. Biol Psychiatry 2008;64:912-915.

[31] Bos MJ, Linden T, Koudstaal PJ, Hofman A, Skoog I, Breteler MM et al. Depressive symptoms and risk of stroke: the Rotterdam study. Neurol Neurosurg Psychiatry 2008;79:997-1001.

[32] Shirai K, Iso H, Ohira T, Ikeda A, Noda H, Honjo K et al. Perceived level of life enjoyment and risks of cardiovascular disease incidence and mortality the Japan Public Health Center-based Study. Circulation 2009;120:956-63.

[33] Nabi H, Koskenvuo M, Singh-Manoux A, Korkeila J, Suominen S, Korkeila $\mathrm{K}$ et al. Low pessimism protects against stroke : the Health and Social Suppport (HeSSup) Prospective Cohort Study. Stroke 2010;41:187-90.

[34] Lahti M, Tiihonen J, Wildgust H, Beary M, Hodgson R, Kajantie E et al. Cardiovascular morbidity, mortality and pharmacotherapy in patients with schizophrenia. Psychological Medicine 2012;42:2275-85.

[35] Tsai K-Y, Lee C-C, Chou Y-M, Su C-Y, Chou F H-C. The incidence and relative risk of stroke in patients with schizophrenia : a five-year follow-up study. Schizophrenia Research 2012;138:41-7.

[36] Majed B, Arveiler D, Bingham A, Ferrières J, Ruidavets JB, Montaye $M$ et al. Depressive Symptoms, a Time-Dependent Risk Factor for Coronary Heart Disease and Stroke in Middle-Aged Men : The PRIME Study. Stroke 2012;43:1761-7.

[37] Feller S, Teucher B, Kaaks R, Boeing H, Vigl M. Life satisfaction and risk of chronic diseases in the European Prospective Investigation into Cancer and Nutrition (EPIC)-Germany Study. PLos One 2013;8(8):e73462.

[38] Bergh C, Udumyan R, Fall K, Nilsagard $Y$, Appelros P, Montgomery S. Stress resilience in male adolescents and subsequent stroke risk : cohort study. J Neurol Neurosurg Psychiatry 2014;85:1331-36. 
[39] Eurelings LSM, Lighthart SA, Van Dalen JW, Van Charante EPM, Van Gool WA, Richard E. Apathy is an independent risk factor for incident cardiovascular disease in the older individual : a population-based cohort study. Int J Geriatr Psychiatry 2014;29:454-63.

[40] Mejia-Lancheros C, Estruch R, Martinez-Gonzalez M, Sales-Salvado J, Castaner O, Corella D et al. Impact of psychosocial factors on cardiovascular morbimortality : a prospective cohort study. BMC Cardiovascular Disorders 2014;14:135.

[41] Hamano T, Li X, Lonn SL, Nabika T, Shiwaku K, Sundquist J et al. Depression, stroke and gender: evidence of a stronger association in men. J Neurol Neurosurg Psychiatry 2015;86:319-23.

[42] Kuper H, Adami H-O, Theorell T, Weiderpass E. The Socioeconomic Gradient in the Incidence of Stroke: A prospective Study in Middle-Aged Women in Sweden. Stroke 2007;38:27-33.

[43] Li C, Hedblad B, Rosvall M, Buchwald F, Khan FA, Engstrom G. Stroke incidence, recurrence and case fatality in relation to socioeconomic position : a population-based study of middleaged Swedish men and women. Stroke 2008;39:2191-96.

[44] McFadden E, Luben R, Wareham N, Bingham S, Khaw K. Social class, risk factors and stroke incidence in men and women : a prospective study in the European Prospective Investigation into Cancer in Norfolk Cohort. Stroke 2009;40:1070-77.

[45] Tsutsumi A, Kayaba K, Ishikawa S. Impact of occupational stress on stroke across occupational classes and genders. Social Science \& Medicine 2011;72:1652-8.

[46] Veronesi G, Ferrario MM, Chambless LE, Sega R, Mancia G, Corrao G et al. Gender differences in the association between education and the incidence of cardiovascular events in Northern Italy. European Journal of Public Health 2011;21(6):762-7.

[47] Gillum RF, Mussolino ME. Education, poverty, and stroke incidence in whites and blacks : the NHANES I Epidemiologic follow-up study. Journal of Clinical Epidemiology 2003;56:188-95.

[48] Yan T, Escarce JJ, Liang L-J, Longstreth WT, Stein-Merkin S, Ovbiagele B et al. Exploring psychosocial pathways between neighbourhood characteristics and stroke in older adults : the cardiovascular health study. Age and Ageing 2013;42:391-7.

[49] Schioler L, Soderberg M, Rosengren A, Jarvholm B, Toren K. Psychosocial work environment and risk of ischemic stroke and coronary heart disease : a prospective longitudinal study of 75236 construction workers. Scand J Work Environ Health 2015;41(3):280-7.

[50] Honjo K, Iso H, Nakaya T, Hanibuchi T, Ikeda A, Inoue M et al. Impact of neighborhood socioeconomie conditions in the risk of stroke in Japan. J Epidemiol 2015;25(3):254-60. 
[51] Andre-Petersson L, Engstrom G, Hedblad B, Janzon L, Rosvall M. Social support at work and the risk of myocardial infarction and stroke in women and men. Social Science \& Medicine 2007;64:830-41.

[52] Ikeda A, Iso H, Kawachi I, Yamagishi K, Inoue M, Tsugane S. Social support and stroke and coronary heart disease : the JPHC Study Cohorts II. Stroke 2008;39:768-75.

[53] Kornerup H, Osler M, Boysen G, Barefoot J, Schnohr P, Prescott E. Major life events increase the risk of stroke but not of myocardial infarction : results from the Copenhagen City Heart Study. Eur J Cardiovasc Prev Rehabil 2010;17(1):113-8.

[54] Nagayoshi M, Everson-Rose SA, Iso H, Mosley TH, Rose KM, Lutsey PL. Social network, social support and risk of incident stroke : atherosclerosis risk in communities study. Stroke 2014;45:2868-73.

[55] Eng PM, Fitzmaurice G, Kubzansky LD, Rimm EB, Kawachi I. Anger Expression and Risk of Stroke and Coronary Heart Disease Among Male Health Professionals. Psychosomatic Medicine 2003;65:100-10.

[56] Everson-Rose S, Roetker NS, Lutsey PL, Kershaw KN, Longstreth WT, Sacco RL et al. Chronic stress, depressive symptoms, anger, hostility and risk of stroke and TIA $n$ the multi-ethnic study of atherosclerosis. Stroke 2014;45:2318-23.

[57] Jood K, Redfors P, Rosengren A, Blomstrand C, Jern C. Self-perceived psychosocial stress and ischemic stroke : a case-control study. BMC Medicine. 2009;7:53-61.

[58] Riaz BK, Chowdhury SH, Karim MN, Feroz S, Selim S, Rahman MR. Risk factors of hemorrhagic and ischemic stroke among hospitalized patients in Bangladesh - a case control study. Bangladesh Med Res Counc Bull 2015;41:29-34.

[59] Engstrom G, Khan FA, Zia E, Jerntrop I, Pessah-Rasmussen H, Norrving et al. Marital dissolution is followed by an increased incidence of stroke. Cerebrovasc Dis 2004;18:31824.

[60] Egido JA, Castillo O, Roig B, Sanz I, Rosa Herrero M, Garay MT et al. Is psycho-physical stress a risk factor for stroke ? A case-control study. J Neurol Neurosurg Psychiatry 2012;83:1104-10.

[61] Grimaud O, Béjot Y, Heritage Z, Vallée J, Durier J, Cadot E et al. Incidence of stroke and socioeconomic neighborhood characteristics : an ecological analysis of Dijon Stroke Registry. Stroke 2011;42:1201-6.

[62] Béjot Y, Guilloteau A, Joux J, Lannuzel A, Mimeau E, Mislin-Tritsch C et al. Social deprivation and stroke severity on admission : a French cohort study in Burgundy and the West Indies-Guyana region. European J of Neurology 2017; doi:1.1111/ene.13271.

[63] Grimaud O, Leray E, Lalloué B, Aghzaf R, Durier J, Giroud M et al. Mortality following stroke during and after acute care according to neighbourhood deprivation : a disease registry study. J. Neurol. Neurosurg. Psychiatry 2014;85:1313-18. 
[64] Kivimäki M, Jokela M, Nyberg S, Singh-Manoux A, Fransson El, Alfredsson L et al. Long working hours and risk of coronary heart disease and stroke : a systematic review and metaanalysis of published and unpublished data for 603838 individuals. The Lancet 2015;386: 1739-46.

[65] Kivimäki M, Nyberg ST, Batty D, Kawachi I, Jokela M, Alfredsson L et al. Long working hours as a risk factor for atrial fibrillation : a multi-cohort study. Europ. Heart Journal 2017;38:262128.

[66] Hannerz H, Albertsen K, Burr H, Lindhardt Nielsen M. Long working hours and stroke among employees in the general work force of Denmark. Scandinavian Journal of Public Health 2017.doi.org/10.1177/1403494817748264.

[67] Leng Y, Cappuccio FP, Wainwright WJ, Surtees PG, Luben R, Brayne C et al. Sleep duration and risk of fatal and non fatal stroke. Neurology 2015;84:1-8.

[68] Theorell T, Hammartstrom A, Aronsson G, Traskman Bendz L, Grape T, Hogstedt C et al. A systematic review including meta-analysis of work environment and depressive symptoms. BMC Public Health 2015;15:738-42.

[69] Araki A, Ito H. Psychological risk factors for the development of stroke in the elderly. J Neurol Neurophysiol 2013;4:147-52.

[70] Lee H-C, Lin H-C, Tsai S-Y. Severely depressed young patients have over five times increased risk for stroke : a 5-year follow-up study. Biol Psychiatry 2008;64:912-15.

[71] Becher H, Dollard MP, Smith P, Li J. Predicting circulatory diseases from psychosocial safety climate : a prospective cohort study from Australia. International Journal of Environmental Research and Public Health 2018;15:415-25.

[72] Tawakol A, Ishai A, Takx RAP, Figueroa AL, Ali A, Kaiser $Y$ et al. Relation between resting amygdalar activity and cardio vascular events : a longitudinal and cohort study. The Lancet 2017;389:834-45

[73] Dimsdale JE. Psychological stress and cardiovascular disease. J Am Coll Cardiol 2008;51:123746.

[74] Feigin VL, Norving B, Mensah GZ. Primary prevention of cardiovascular disease through population-wide motivational strategies : insights from using smartphone in stroke prevention. BMJ Global Health 2017 Doi:10.1136/bmjgh-2017-000306.

[75] Henderson KM, Clark CJ, Lewis TT, Aggarwal NT, Beck T, Guo H et al. Psychosocial distress and stroke risk in older adults. Stroke 2013;44:367-372.

[76] Tan M, Morgan K. Psychological interventions in cardiovascular disease : an update. Curr Opin Psychiatry 2015;28:371-7. 
[77] Lawrence M, Booth J, Mercer S, Crawford E. A systematic review of the benefits of mindfulness-based interventions following transient ischemic attack and stroke. Int J Stroke 2013;8:465-74.

[78] Price AJ, Wright FL, Green J, Balkwill A, Wan Kan S, Yang TO et al. Differences in risk factors for 3 types of stroke. UK prospective study and meta-analyses. Neurology 2018. doi.10.1212/WNL.04856. 
Table 1: Characteristics of cohort studies

\begin{tabular}{|c|c|c|c|}
\hline \multicolumn{2}{|l|}{ Psychological risks } & \multicolumn{2}{|l|}{ Occupational risks } \\
\hline Author (year) (ref) & $\begin{array}{c}\text { Risk estimation } \\
\text { HR (95\% Cl) }\end{array}$ & Author (year) (ref) & $\begin{array}{c}\text { Risk estimation } \\
\text { HR (95\% Cl) }\end{array}$ \\
\hline 1) Ohira et al $(2001)^{18}$ & $1.90(1.10-3.50)$ & 1) Kuper et al (2007) ${ }^{42}$ & $1.50(1.00-2.20)$ \\
\hline 2) May et al (2002) & $1.26(0.85-1.85)$ & 2) Li et al $(2008)^{43}$ & \\
\hline 3) Truelsen et al $(2003)^{20}$ & $1.13(0.85-1.50)$ & men & $1.29(1.06-1.58)$ \\
\hline 4) Ohlin et al $(2004)^{21}$ & $1.29(1.04-1.60)$ & women & $1.75(1.36-2.25)$ \\
\hline 5) Nilsson et al $(2004)^{22}$ & $1.22(1.06-1.41)$ & 3) Mac Fadden et al (2009) ${ }^{44}$ & $2.55(1.34-4.85)$ \\
\hline 6) Curkendall et al $(2004)^{23}$ & $1.50(1.20-2.00)$ & 4) Tsutsumi et al $(2011)^{45}$ & \\
\hline 7) Araki et al $(2004)^{24}$ & $2.70(1.10-6.80)$ & men & $2.80(1.20-6.40)$ \\
\hline 8) Smoller et al $(2007)^{25}$ & $1.98(0.75-5.24)$ & women & $1.30(0.60-3.00)$ \\
\hline 9) Lin et al $(2007)^{26}$ & $2.05(1.73-3.54)$ & 5) Veronesi et al $(2011)^{46}$ & \\
\hline 10) Salaycik et al (2007) 27 & & men & $2.18(1.26-3.78)$ \\
\hline$<65$ years & $3.43(1.60-7.36)$ & women & $0.40(0.20-0.85)$ \\
\hline$>65$ years & $0.78(0.46-1.34)$ & 6) Gillum et al (2012) ${ }^{47}$ & \\
\hline 11) Arbelaez et al $(2007)^{28}$ & $1.25(1.02-1.53)$ & white men & $0.80(0.57-1.12)$ \\
\hline 12) Surtees et al(2008) $)^{29}$ & $1.08(0.67-1.75)$ & black people & $0.70(0.46-1.08)$ \\
\hline 13) Lee et al $(2008)^{30}$ & $5.43(3.47-8.51)$ & 7) Tsai et al $(2012)^{35}$ & $1.16(1.01-1.33)$ \\
\hline 14) Bos et al $(2008)^{31}$ & $1.21(0.80-1.83)$ & 8) Yan et al $(2013)^{48}$ & $1.14(0.86-1.52)$ \\
\hline 15) Shirai et al (2009) ${ }^{32}$ & & 9) Mejia-Lancheros et al $(2014)^{40}$ & $1.83(1.09-3.09)$ \\
\hline men & $1.22(1.01-1.47)$ & 10) Schioler et al $(2015)^{49}$ & $1.13(0.95-1.34)$ \\
\hline women & $1.09(0.86-1.37)$ & 11) Honjo et al $(2015)^{50}$ & $1.05(0.90-1.23)$ \\
\hline 16) Nabi et al $(2010)^{33}$ & $0.52(0.29-0.93)$ & 12) Fransson et al $(2015)^{11}$ & \\
\hline 17) Lahti et al $(2012)^{34}$ & $1.69(0.90-3.16)$ & ischemic stroke & $1.24(1.05-1.47)$ \\
\hline 18) Tsai et al $(2012)^{35}$ & $1.13(1.06-1.22)$ & hemorrhagic stroke & $1.01(0.75-1.36)$ \\
\hline 19) Majed et al (2012) 36 & $1.41(0.95-2.11)$ & 13) Huang et al $(2015)^{13}$ & \\
\hline 20) Feller et al $(2013)^{37}$ & & men & $1.33(1.04-1.69)$ \\
\hline men & $1.40(0.89-2.19)$ & & $1.26(0.69-2.27)$ \\
\hline women & $1.69(1.05-2.73)$ & & \\
\hline 21) Bergh et al (2014) & $1.16(1.04-1.29)$ & & \\
\hline 22) Eurelings et al $(2014)^{39}$ & $1.74(0.89-3.38)$ & & \\
\hline 23) Mejia-Lancheros et al $(2014)^{40}$ & $0.66(0.38-1.15)$ & & \\
\hline 24) Hamano et al $(2015)^{41}$ & $1.22(1.08-1.38)$ & & \\
\hline
\end{tabular}


Table 2. Characteristics of cohort studies

\begin{tabular}{|c|c|c|c|}
\hline \multicolumn{2}{|c|}{ Interpersonal risks } & \multicolumn{2}{|c|}{ Behavioral risks } \\
\hline Author (year) (ref) & $\begin{array}{c}\text { Risk estimation } \\
\text { HR }(95 \% \mathrm{Cl})\end{array}$ & Author (year) (ref) & $\begin{array}{c}\text { Risk estimation } \\
\text { HR }(95 \% \mathrm{Cl})\end{array}$ \\
\hline 1) Araki et al $(2004)^{24}$ & $3.20(1.30-7.80)$ & 1) Eng et al $(2003)^{55}$ & $0.42(0.20-0.88)$ \\
\hline 2) André-Peterson et al (2007) 51 & $1.80(1.05-3.10)$ & 2) Everson-Rose et al $(2014)^{56}$ & $2.00(1.15-3.47)$ \\
\hline 3) Kuper et al (2007) $)^{42}$ & $1.30(0.90-1.80)$ & & \\
\hline 4) Ikeda et al $(2008)^{52}$ & $1.11(0.89-1.37)$ & & \\
\hline 5) Kornerup et al (2010) ${ }^{53}$ & $1.32(0.77-2.25)$ & & \\
\hline 6) Yan et al (2013) & $1.02(0.98-1.07)$ & & \\
\hline 7) Mejia-Lancheros et al $(2014)^{40}$ & $0.56(0.28-1.12)$ & & \\
\hline 8) Nagayoshi et al $(2014)^{54}$ & $1.44(1.02-2.04)$ & & \\
\hline
\end{tabular}


Table 3. Characteristics of case-control studies

\begin{tabular}{|l|l|l|}
\hline & \multicolumn{1}{|c|}{ Author (year) (ref) } & \multicolumn{1}{|c|}{$\begin{array}{c}\text { Risk estimation } \\
\text { HR (95\% Cl) }\end{array}$} \\
\hline Psychological risks & Jood et al (2009) [57] & $2.51(1.42-4.44)$ \\
& Riaz et al (2015) [58] & $4.14(1.54-11.09)$ \\
\hline Interpersonal risks & Engstrom et al (2004) [59] men & $1.23(1.03-1.50)$ \\
& Engstrom et al (2004) [59] women & $0.98(0.84-1.20)$ \\
& Egido et al (2012) [60] & $3.84(1.91-7.70)$ \\
\hline Social deprivation & Grimaud et al (2011) [61] & $2.08(1.07-4.02)$ \\
& Béjot et al (2017) [62] & $1.39(1.06-1.84)$ \\
\hline Whole psychosocial risks & O'Donnell et al (2016) [5] & $2.20(1.78-2.72)$ \\
\hline
\end{tabular}


Table 3: Meta-analyses

\begin{tabular}{|l|c|}
\hline \multicolumn{1}{|c|}{ Author (year) (ref) } & Risk estimation HR (95 \% Cl) \\
\hline Lightbody et al (2017) & $1.35(1.20-1.51)$ \\
Booth et al (2015) & $1.33(1.17-1.50)$ \\
\hline
\end{tabular}

